\title{
The effect of alloying on the ordering processes in near-alpha titanium alloys
}

\author{
Artemiy Popov*, Natalya Rossina, Maria Popova \\ Ural Federal University named after the first President of Russia B.N. Yeltsin, 19 Mira Street, Ekaterinburg 620002, Russia
}

\section{A R T I C L E I N F O}

\section{Article history:}

Received 11 July 2012

Received in revised form

10 October 2012

Accepted 14 November 2012

Available online 23 November 2012

\section{Keywords:}

Titanium alloys

Aging

Ordering

Phase transformation

Precipitation

Electron microscope

\begin{abstract}
A B S T R A C T
The substructure of near-alpha Ti-Al-Sn-Zr-Mo-Si alloys containing up to 12.5 at\% aluminum was studied by transmission electron microscopy (TEM). It was shown that long-range order sections are formed at aging temperatures up to $500{ }^{\circ} \mathrm{C}$ in alloys, high in aluminum, and the ordered phase is formed by the nucleation and growth mechanism at $700{ }^{\circ} \mathrm{C}$ aging temperatures. Causes of changing the phase transformation mechanism have been discussed, and the relationship between the structure and properties of alloys, depending on modes of heat treatment has been analyzed. Also the influence of aluminides and silicides precipitation on the mechanical alloy properties after aging was examined. It was shown that the aluminide formation led to a slight hardening and a significant viscosity decrease. The silicide particles formation reduced the heat resistance properties, due to the depletion of the solid solution by silicon.
\end{abstract}

(c) 2012 Elsevier B.V. All rights reserved.

\section{Introduction}

The structural investigation of heat-resistant titanium alloys is usually focused on the morphology and behavior of the main phases $-\alpha$ and $\beta$. However, in these alloys, both different silicide particles can be released [1,2], and formation of $\mathrm{Ti}_{3} \mathrm{Al}$ particles in $\alpha$ phase can happen $[3,4]$. All these precipitates can significantly have an effect on the properties of the alloys. For example, the selection of $(\mathrm{Ti}, \mathrm{Zr})_{5} \mathrm{Si}_{3}$ silicides on the interface $\alpha / \beta$ boundaries decreases the technological plasticity of the alloys [1], and the formation of $(\mathrm{Ti}, \mathrm{Zr})_{6} \mathrm{Si}_{3}$ particles in the body of $\alpha$-phase decreases the characteristics of heat resistance [2]. The technological plasticity reduction is due to the stress raisers appearance at the interfaces, and heat resistance decrease is due to the depletion of solid solution by silicon and zirconium. In cases when the ordering processes occur in the $\alpha$-phase and $\mathrm{Ti}_{3} \mathrm{Al}$ particles ( $\alpha_{2}$-phase) are formed, heat resistance characteristics increase, but plastic properties degrade dramatically [3]. Mutual influence of $\alpha$-phase and silicides [2,5] determines the complexity of formed properties. However, the formation of $\alpha_{2}$-phase may occur not as isolated particles, the formation of which is carried out by the mechanism of nucleation and growth, but may result from the second kind of phase transformation as a consequence of the ordering processes. In this case, the complex properties of heatresistant titanium alloys on the basis of $\alpha$-solid solution will be largely determined by the mechanism leading to the formation

\footnotetext{
* Corresponding author. Tel.: +7 343 3745964; fax: +7 3433754803 .

E-mail addresses: p.artemii@mail.ru, a.a.popov@ustu.ru (A. Popov), pmaria777@mail.ru (M. Popova).
}

of $\left(\alpha+\alpha_{2}\right)$-structure. In this context, the aim of this paper is to study the mechanisms of $\alpha_{2}$-phase domains formation depending on the temperature -time parameters of heat treatment.

\section{Materials and experimental procedure}

Experimental Ti-Al-Sn-Zr-Mo-Si alloys, containing up to 12.5 at\% aluminum were used. Aluminum alloy equivalent ranged from 8 to 10.5 , with the $\beta$-stability conditional factor of 0.7 . The deformation of $20 \mathrm{~kg}$ ingots was performed using standard technology, which involves a combination of forging in $\beta$-region and then rolling in $\beta$-region at $\beta_{\mathrm{T}}+100{ }^{\circ} \mathrm{C}$. Final deformation of the alloys was carried out by rolling in a two-phase region at temperatures $\beta_{\mathrm{T}}$ $-(20-30){ }^{\circ} \mathrm{C}$. The heat treatment of alloy was performed using an electro-contact technique up to $t 1150{ }^{\circ} \mathrm{C}$ with $30 \mathrm{~s}$ time delay followed by air cooling. Aging was carried out at $t 500-700{ }^{\circ} \mathrm{C}$ with soaking for $1-100 \mathrm{~h}$ in a laboratory muffle furnace.

The structure was studied in samples cut perpendicular to the rolling direction. The main investigation methods were diffraction and scanning electron microscopy, performed on JEM-2100C and JSM6490 with energy analyzers, respectively. X-ray diffraction analysis was performed using a diffractometer "Bruker D8 Advance" with the $\mathrm{Cu} \mathrm{K} \alpha$ radiation.

\section{Results and discussion}

Electron microprobe analysis of alloys following electric heating showed that such rapid heating and short exposure time led to 
insufficient time for homogenization of the composition in formed $\beta$ grains and material with heterogeneous composition is subjected to cooling. For example, in the alloy containing 12.5 at\% aluminum, the difference in the concentrations of aluminum reached 2 at\% in different regions, formed during $\alpha$ plates cooling. However, a lamellar structure was formed in all cases.

During the TEM observation, heterogeneous lamellar $(\alpha+\beta)$ structure was also observed.

The plates of $\alpha$ and $\beta$ phases with a low density of defects and with perfect interfaces within them are visible in separate microvolumes (Fig. 1a, b), while in others, there is an increased density of imperfections in the crystal structure (Fig. 1c); $\alpha_{2}$-phase reflections are visible on the electron images; however, individual particles were not detected (Fig. 1d). These reflections can be seen more brightly for alloys having a higher aluminum equivalent.

In the alloy having a low content of aluminum (aluminum equivalent of 8 ), the reflections from $\alpha_{2}$-phase are not observed.

The results of mechanical tests of alloys after electric heating and aging at various temperatures are presented in Table 1 . As the presented results show, in all alloys, aging at $500{ }^{\circ} \mathrm{C}$ is not accompanied by noticeable hardening and decrease in viscosity and plastic properties. At higher aging temperatures, the hardening of alloys is also quite low, and it is manifested mainly at $600{ }^{\circ} \mathrm{C}$ and at $100 \mathrm{~h}$ delay. As compared to the initial state, the strength increases by about $50-100 \mathrm{MPa}$; depending on the alloy composition, plasticity is slightly reduced, while the viscosity decreases significantly (and after aging at $700{ }^{\circ} \mathrm{C}$ fracture energy reduced almost to zero).
A lamellar $(\alpha+\beta)$-structure is also observed in the aged state in all alloys. In addition, during aging there is a precipitation of silicide particles, which are mainly located at the interface $\alpha / \beta$ boundaries on the part of $\beta$-phase and have the structural formula of $(\mathrm{Ti}, \mathrm{Zr})_{5} \mathrm{Si}_{3}$ with hexagonal lattice (Fig. 2).

In the literature, these silicides are denoted as $\mathrm{S}_{1}$. Sometimes silicide particles are located inside separate $\alpha$ phase globules. Then their structural formula corresponds to $(\mathrm{Ti}, \mathrm{Zr})_{6} \mathrm{Si}_{3}$, due to the increased zirconium content in these particles. These silicides are denoted as $\mathrm{S}_{2}$. Allocation of silicides is observed in the alloys aged at $600-700{ }^{\circ} \mathrm{C}$. The amount of silicide particles in the alloys aged for $100 \mathrm{~h}$ both at 600 , and at $700{ }^{\circ} \mathrm{C}$ is approximately the same. As shown in $[2,6]$, the selection of silicide particles on the interface boundaries $\left(\mathrm{S}_{1}\right)$ causes a decrease in the work required for crack extension.

In alloys, where the aluminum equivalent is more than 9, reflections from the $\alpha_{2}$-phase are always clearly observed. Their intensity increases with the aging time but poorly depends on aging temperature $\left(500-700{ }^{\circ} \mathrm{C}\right)$. In the structure of alloys with aluminum equivalent of $8.0-9.2$, aged at $t 500{ }^{\circ} \mathrm{C}$, there are crystal structure defects, similar to the dislocation (Fig. 3a), and in an alloy with aluminum equivalent of 10.5 , antiphase boundaries are visible in separate micro-volumes (Fig. $3 \mathrm{~b}$ ) which clearly indicate the processes of ordering. In our opinion, the defects observed in Fig. 3 are also fragments of antiphase boundaries. Microstructure data indicate improvements of ordered structure, the formation of which is the result of a homogeneous transformation, the particles being formed without the nucleation and growth mechanism.
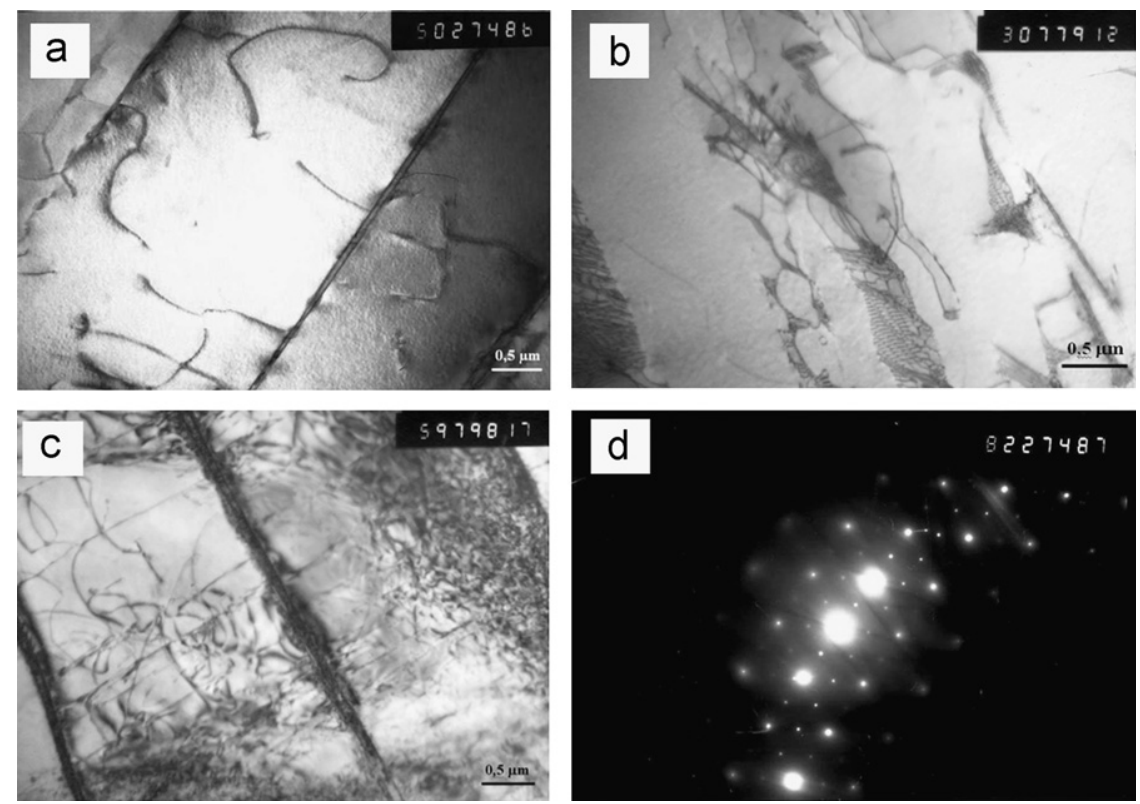

Fig. 1. Bright-field TEM images of quenched alloys and (d) the corresponding SAD pattern generated from the area (c).

Table 1

Mechanical properties of alloys.

\begin{tabular}{|c|c|c|c|c|c|c|c|c|c|}
\hline \multirow[t]{3}{*}{ Heat treatment } & \multicolumn{9}{|l|}{$[\mathrm{Al}]_{\mathrm{eq}}$} \\
\hline & \multicolumn{3}{|c|}{$\begin{array}{l}\text { Tensile strength } \sigma_{\mathrm{B}} / \text { yield } \\
\text { strength } \sigma_{0,2}(\mathrm{MPa})\end{array}$} & \multicolumn{3}{|c|}{$\begin{array}{l}\text { Tensile strain } \delta / \text { contraction } \\
\psi(\%)\end{array}$} & \multicolumn{3}{|c|}{$\begin{array}{l}\text { Toughness } \mathrm{KCU} / \text { fracture } \\
\text { energy } \mathrm{KCT}\left(\mathrm{MJ} / \mathrm{m}^{2}\right)\end{array}$} \\
\hline & 8 & 9 & 10.5 & 8 & 9 & 10 & 8 & 9 & 10 \\
\hline $1150{ }^{\circ} \mathrm{C}-30 \mathrm{~s}$-air & $924 / 835$ & $940 / 859$ & $994 / 882$ & $13.4 / 31.4$ & $17.2 / 31.5$ & $15.6 / 28.6$ & $0.59 / 0.51$ & $0.67 / 0.41$ & $0.49 / 0.22$ \\
\hline $1150{ }^{\circ} \mathrm{C}-30$ s. - air $+500{ }^{\circ} \mathrm{C}-100 \mathrm{~h}$-air & $952 / 875$ & $935 / 857$ & $1020 / 941$ & $17.1 / 27.8$ & $18.6 / 30.1$ & $13.2 / 20.0$ & $0.56 / 0.35$ & $0.62 / 0.3$ & $0.38 / 0.1$ \\
\hline $1150{ }^{\circ} \mathrm{C}-30 \mathrm{~s}-\mathrm{air}+600^{\circ} \mathrm{C}-10 \mathrm{~h}$ - air & $950 / 875$ & $947 / 878$ & $1036 / 961$ & $14.8 / 29.7$ & $17.3 / 28.6$ & $11.3 / 23.5$ & $0.54 / 0.34$ & $0.55 / 0.27$ & $0.32 / 0.07$ \\
\hline $1150{ }^{\circ} \mathrm{C}-30 \mathrm{~s}-$ air $+600^{\circ} \mathrm{C}-100 \mathrm{~h}$-air & $968 / 907$ & $980 / 909$ & $1066 / 995$ & $15.5 / 26.1$ & $10.2 / 17.1$ & $5.1 / 8.8$ & $0.43 / 0.21$ & $0.47 / 0.18$ & $0.22 / 0.06$ \\
\hline $1150{ }^{\circ} \mathrm{C}-30 \mathrm{~s}-$ air $+700^{\circ} \mathrm{C}-100 \mathrm{~h}-$ air & $925 / 883$ & $939 / 866$ & $1065 / 949$ & $12.5 / 21.2$ & $14.2 / 27.8$ & $7.1 / 10.9$ & $0.40 / 0.23$ & $0.41 / 0.20$ & $0.14 / 0.05$ \\
\hline
\end{tabular}



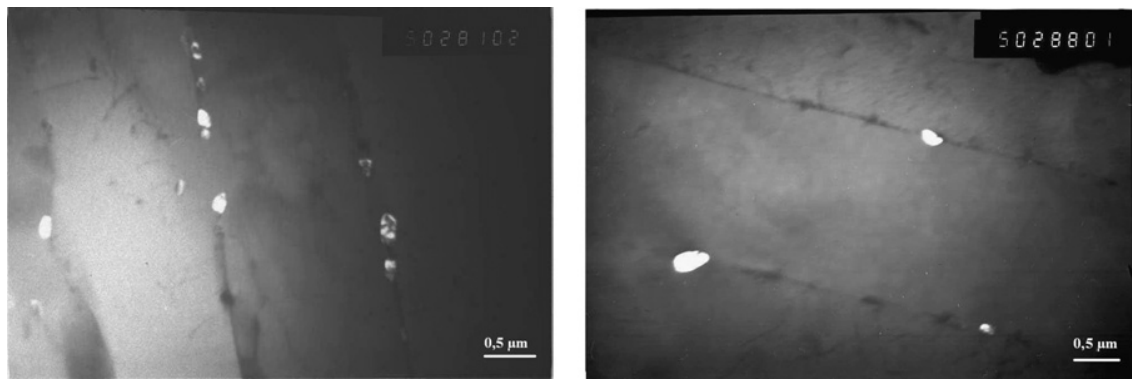

Fig. 2. TEM dark-field images showing $S_{1}$ silicide precipitation on the interface $\alpha / \beta$ boundary.
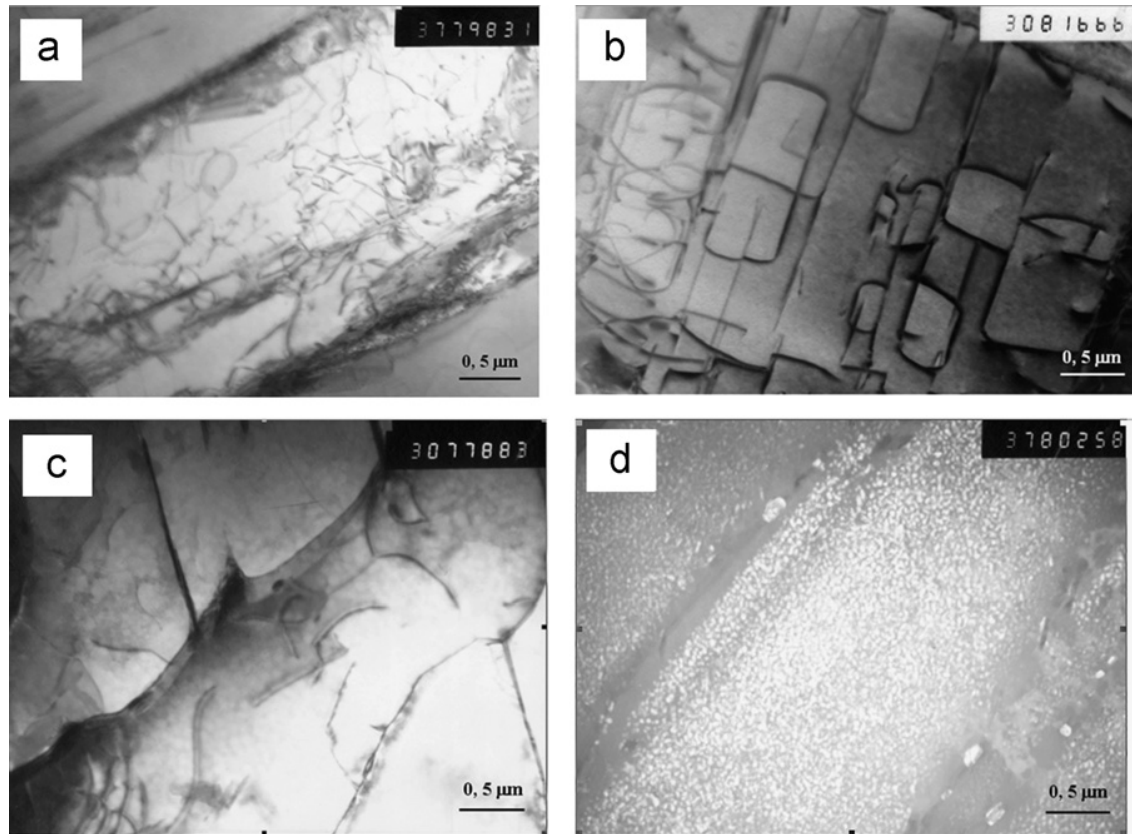

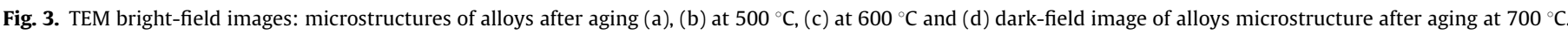

The formation of such structures does not cause any significant reduction of alloys viscosity.

In the case of aging at $600{ }^{\circ} \mathrm{C}$ we failed to observe the antiphase boundaries, but in separate micro-volumes pair the dislocation is observed (Fig. 3c). Reflections from the $\alpha_{2}$-phase are also observed for all investigated alloys, but their intensity is lower than that after aging at $500{ }^{\circ} \mathrm{C}$. Separate dispersed particles were not found.

For the alloys aged at $700{ }^{\circ} \mathrm{C}$, the precipitation of separate $\alpha_{2^{-}}$ phase particles was clearly observed. These particles were evenly distributed throughout the body of the grain (Fig. 3d). They were formed by the mechanism of nucleation and growth, i.e. in a heterogeneous way. As a result of the particles precipitation there is a disastrous decrease in the toughness characteristics.

Thus, electron-microscopic study of the alloys structure has shown that as a result of micro-diffraction analysis the $\alpha_{2}$ phase is present in the alloys after all the treatments studied. However, the relative intensity of the reflections from the $\alpha_{2}$-phase increases in the alloys in the aged condition compared with alloys air cooled from the $\beta$-region, while the intensity of the reflections in the alloys with the aluminum equivalent of more than 9.0 after aging, both after $500{ }^{\circ} \mathrm{C}$ and after $700{ }^{\circ} \mathrm{C}$, is practically identical. At the same time, isolated $\alpha_{2}$-phase particles are observed in the alloys only after aging at $700{ }^{\circ} \mathrm{C}$, and after aging at $500{ }^{\circ} \mathrm{C}$ there are areas where antiphase boundaries are visible. The number of these areas increases with the aging time and a higher aluminum equivalent, i.e. ordering proceeding by the mechanism of homogeneous transformations takes place.
The results are consistent with the results of [7], where the mechanism of ordering in binary titanium-aluminum alloys is theoretically considered. Based on the analysis of the change in free energy, depending on the degree of long-range order and temperature, the authors showed that there were two temperatures $T_{0}$ and $T_{\mathrm{S}}$, which characterized the possible mechanisms of transformation. The temperature $T_{0}$ corresponds to the critical temperature and characterizes the equality of free energies of phases $\alpha$ and $\alpha_{2}$. But unlike the usual representations of $T_{0}$, when the curves of the free energies intersect, in this case there is a "detachment" from the curve of free energy of a disordered alloy, characterizing the ordered phase. Temperature $T_{\mathrm{S}}$ corresponds to the point of inflection in the dependence of the free energy on the degree of order and, therefore, defines the region of instability of the ordered phase. The calculations showed that the temperature $T_{\mathrm{S}}<T_{0}$. For example, Fig. 4 shows the effect of concentration on the position of the temperatures $T_{\mathrm{S}}$ and $T_{0}$ [7].

Fig. 4 shows that when the alloy is in region 1 , then for the nucleation of $\alpha_{2}$-phase, the composition fluctuations are required, since $T>T_{0}$ and the ordered phase has higher energy. At $T<T_{\mathrm{S}}$ (Region III), any order degree fluctuation is energetically favorable and the formation of $\alpha_{2}$-phase should occur by homogeneous mechanism, which is representative for second kind phase transitions. In the $\left(T_{0}-T_{\mathrm{S}}\right)$ interval (Region II) two mechanisms of transformation can occur.

Using the results of [7], temperatures $T_{0}$ and $T_{\mathrm{S}}$ were estimated for the experimental alloys. Alloys were considered as binary 


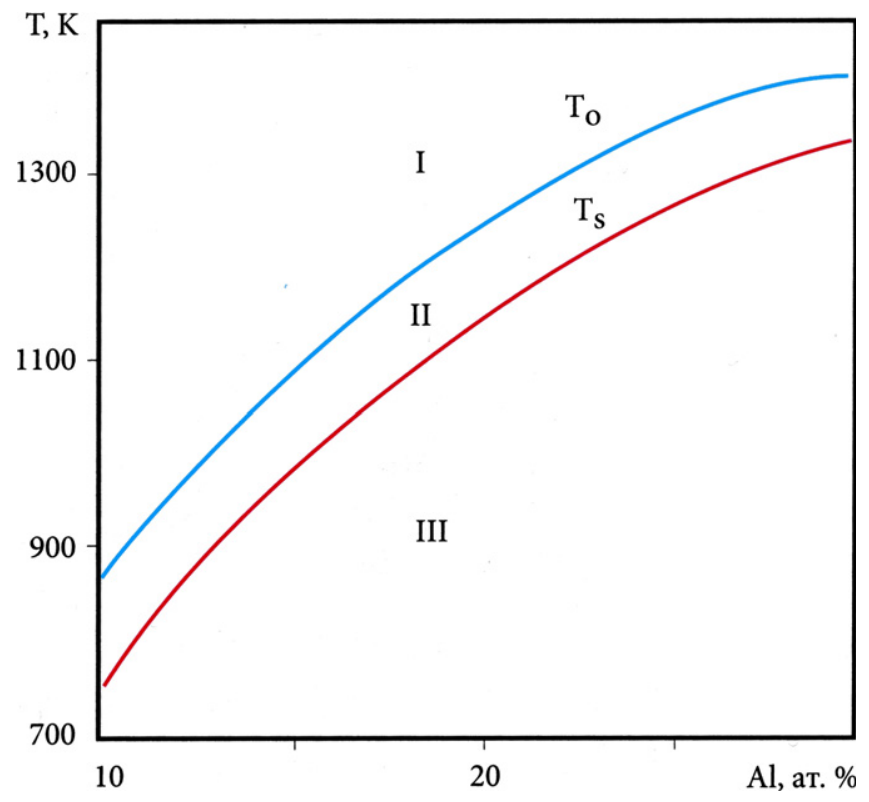

Fig. 4. Influence of aluminum concentration on $T_{0}$ and $T_{\mathrm{S}}$ temperatures [7]. $T_{0}$-the critical temperature of the $\alpha$ - and $\alpha_{2}$-phases free energies equality and $T_{\mathrm{S}}$ - the temperature of loss of solid solution absolute stability.

titanium-aluminum systems. The temperature $T_{0}$ is in the 550-620 ${ }^{\circ} \mathrm{C}$ range depending on the composition, and the temperature $T_{\mathrm{S}}$ in 620-680 ${ }^{\circ} \mathrm{C}$, which agrees with the experimental data presented above. Consequently, the results of [7] confirm that at $500{ }^{\circ} \mathrm{C}$ the formation of $\alpha_{2}$ structure is the result of ordering by the homogeneous transformation, and at $700{ }^{\circ} \mathrm{C}$-the process occurs by the mechanism of nucleation and growth with the formation of dispersed particles of $\alpha_{2}$-phase. When the aging temperature is $600{ }^{\circ} \mathrm{C}$, both mechanisms of transformation are possible.

\section{Conclusions}

1. It was found that at low aging temperatures $\left(500{ }^{\circ} \mathrm{C}\right)$ the formation of $\alpha_{2}$-phase occurs due to separate micro-volumes ordering by the homogeneous mechanism due to the inhomogeneity of the initial state with the characteristic formation of antiphase boundaries. The increase of the aging temperature to $700{ }^{\circ} \mathrm{C}$ helps to activate the diffusion processes and contributes to the formation of $\alpha_{2}$-phase by the mechanism of nucleation and growth.

2. It was confirmed that the structural type $S_{1}$ silicides were formed at the interface $\alpha / \beta$ boundaries on the part of $\beta$ phase, and silicides such as $S_{2}$ and $S_{3}$ were formed in the $\alpha$ phase.

3. The influences of the aluminides and silicides precipitation on alloys mechanical properties during aging were investigated. It was shown that their formation leads to a slight hardening and a significant decrease in viscosity properties. Plastic characteristics are only moderately changed.

\section{References}

[1] A.A. Popov, N.A. Drozdova, J. Appl. Math. Mech. (PMM) 84 (1997) 407-412.

[2] A.A. Popov, N.A. Drozdova, O.A. Elkina, A.V. Trubochkin Titanium'99: Science and Technology, Proceedings of the 9th World Conference of Titanium/CRISM Prometey, 2000, pp. 563-570.

[3] T.N. Kochetkova, A.B. Notkin, E.I. Teitel., J. Appl. Math. Mech. (PMM) 69 (1990) $176-182$.

[4] J.D. Evans, T.F. Broderick, J.B. Woodhouse, J.R. Hoeniman., Titanium'95: Science and Technology, Proceedings of the 8th World Conference of Titanium, Birmingham, 1995, pp. 2413-2420.

[5] A.A. Popov, N.A. Drozdova, A.V. Trubochkin, O.A. Elkina, J. Appl. Math. Mech. (PMM) 87 (1999) 58-63.

[6] C. Ramachandra, V. Singh., Met. Trans. A 2 (1992) 689-690.

[7] S.P. Belov, A.A. Il'in, A.M. Mamonov, Metals 1 (1994) 134-137. 